\title{
4-(Methylnitrosamino)-1-(3-Pyridyl)-1- Butanol
}

National Cancer Institute

\section{Source}

National Cancer Institute. 4-(Methylnitrosamino)-1-(3-Pyridyl)-1-Butanol. NCI Thesaurus. Code C127127.

The major metabolite of the potentially carcinogenic nitrosamine 4-methylnitrosamino1,3-pyridyl-1-butanone (nicotine-derived nitrosamine ketone; NNK) that is detected in the urine of subjects exposed to tobacco products. 4-(methylnitrosamino)-1-(3-pyridyl)-1butanol (nicotine-derived nitrosamine alcohol; NNAL) is produced by carbonyl reduction of NNK and may also be a carcinogen. 